\title{
Linear megastructures. An eccentric pursuit in tackling urban sustainability challenges
}

\section{Abstract}

A development. The term refers to various compact architectural, infrastructural and transpotration plans in linear form. With their daunting massive scale these concepts are often attributed to utopian attempts of pursuing an ideal city and therefore doomed to remain unrealized. This paper examines several models created throughout the course of history in terms of their

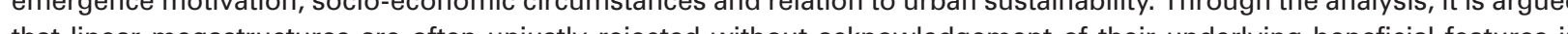
terms of mitigating challenges to sustainable urban development.

Key words: linear, megastructure, utopia, transit-oriented

1. Definition of linear megastructure Linear megastructures in terms of urbanism is a term coined as part of a broader research on linear urban planning titled "Contemporary linear city development. A case of spatial interventions in Sarajevo, BiH" aiming to highlight the diversity of approaches to the idea of linearity in urban planning, indicate their similarities, establish a distinction of linear concepts on different scale levels, historical context, design approach, spatial characteristics and feasibility in tackling urban sustainability challenges on a given case study.

In general scope, the research provides a categorization of several types of linear urban development within theory of urban planning in accordance with the following characteristics:

. Concept - whether existing or only theoretical

2. Form induing fant - planned or unplanned

socio-economic drive

Organization - a single

mpact urban setting or part

Transportation

ion - ratio of transportation mode to size of development, transportation system (single or The recognized

by these characteristics are:

1. Coincidental linear urban forms,

2. Linear villages,

4. Linear megastructures,

5. Transit-oriented developments (TOD) and

6. Infrastructure corridors.

In accordance to the aforementioned characteristics linear megastructures in general are theoretical, socio- -economically driven forms of planned, multimodal, compact linear development concepts with a directly proportional ratio of size to transportation mode.

Linear megastructures are therefore defined as a compact form of linear urban development in continuous built structure. Zoning of functions is usually vertically distributed below or above transportation spine, different from other linear development concepts where form and structure re arranged in planar configuration." (Tufek-Me-

This research, nonetheless, provides a more detaled historical overview of such precedents empha位ing their disadvantages and advantages in porow th of urban spaces. Ideas of compact linear ure and attributed to utopian planning ideology or viewed as a product of utilitarian uniformity of modernist thinking. The daunting massive scale of such concepts makes them unappealing and living in them seemingly unrealistic, inhumane even -" megastructures would be landmarks to the menta fossilization of humankind." (Cathacart, 1996) In other instances they are regarded as "heroic am bition" of creating environments that serve as model cities (Lin, 2007, 74) However, the idea of multilevel cities following a certain transportation route is one suggested by some of the greatest minds in history and dates long before Modernism. Furthermore, most of the linear megastructure concepts mainly arose from the motivation of mitigating challenges to sustainable urban development and combating causes that deteriorate living for inhabitants. A few of the features presented in these concepts already exist in certain urban areas, and some contemporary answers to urban conditions consist of similar approaches. It points to the question: In the era of big data, accelerated urban growth, unprecedented engineering achievements, realistic plans of "Hyperloop" transportation and colonialization of another planet, whether a concept of linear megastructure is still a completely
unrealistic one?!

Precedent concepts of multilevel transit-oriented cities The $15^{\text {th }}$ century black plague outbreak in Milan, Italy which took tens of thousands of lives, motivated Leonardo Da Vinci- one of the greatest Homo Universalis in dealing with the epicemic. the narrow, crowded and dity medieval streets of Milan with their hard to navigate layout contributed to the spread of the disease, so he proposed a plan for the reconstruction of the city consistent with Renaissance ideas yet innovative and extravagant at the time. The series of drawings, notes and ingenious thoughts around this city plan can be found in the largest assembled collection of Da Vinci's papers called "The Paris Manuscrip B" and "Code Atlanticus."

The reconstruction plan Da Vinci proposed was designed around Ticino River and consisted of a multi-level vertical division of the city in terms of functionality or "zoning" and a network of canals for commerce and sanitation (III. 1). By placing vertical communication on the outside of building walls an undisturbed circulation of pedestrians was made possible between the upper leve elegant streets and palaces. This area was reserved for the gentiluomini, while the lower levels were dedicated to the poveraglia, service, transportation and trade. (Kostof, 1992, 237). The underground level consisted of canals linked directly to building basements for ea-

III. 1. Leonardo Da Vinci Sheme for a multilevel circulation system for Milan ca 1490 (Source: Kostof, 1992)
III. 2. Eugène Hénard, Scheme of a multilevel heavy traffic street in "Streets of the Future" 1910 (Source: $h$

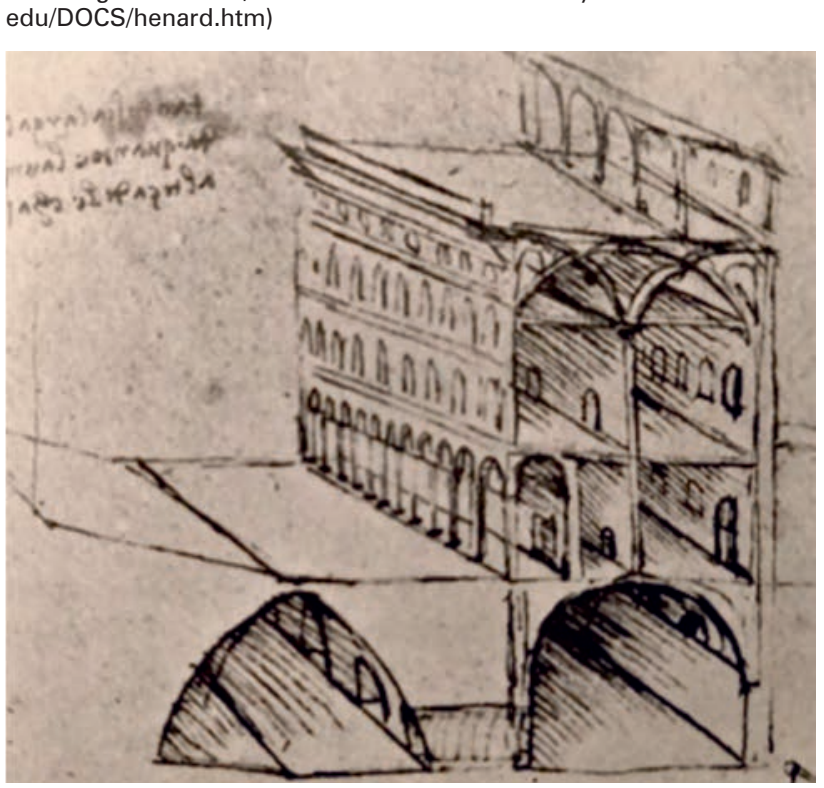

sier unloading of goods. A significant feature of the artificial can and them. Although there is an unfortunate social segregation within the designated spaces, whether due to plague prevention or simply a characteristic of the times, the concept aims to provide cleaner and organized urban spaces altogether.

However, the scope of execution of Da Vinci's un conventional vision of the ideal city was too broad, since it would have required entirely rebuilding existing ciltes or forming completely new ones mained unrealized.

One of the most prominent name in French town planning of the last century Eugène Hénard presented a vision of future cities based on the streets of Paris at the Royal Institute of British Architects, Town Planning Conference in London in 1910. Hénard's critique of the existing city streets was largely focused on infrastructural problems that became hardly sustainable within their existing framework and longed for a revisionist solution to the challenges. Problems that arose as technological advancements are made, such as distribution of electrical and telephone lines that were intertwined with sewers initially constructed only for wastewater removal, became harder to maintain and continuous interventions on them disturbed street circulation, pedestrian movement and supply of goods. Waste, smoke and ash disposal from the buildings contributed to city pollution and lower quality of living for inhabitants.

Mest on deaing with the issue of infrastructure through implementarion of sustainable and healthier living conditions. Nevert-

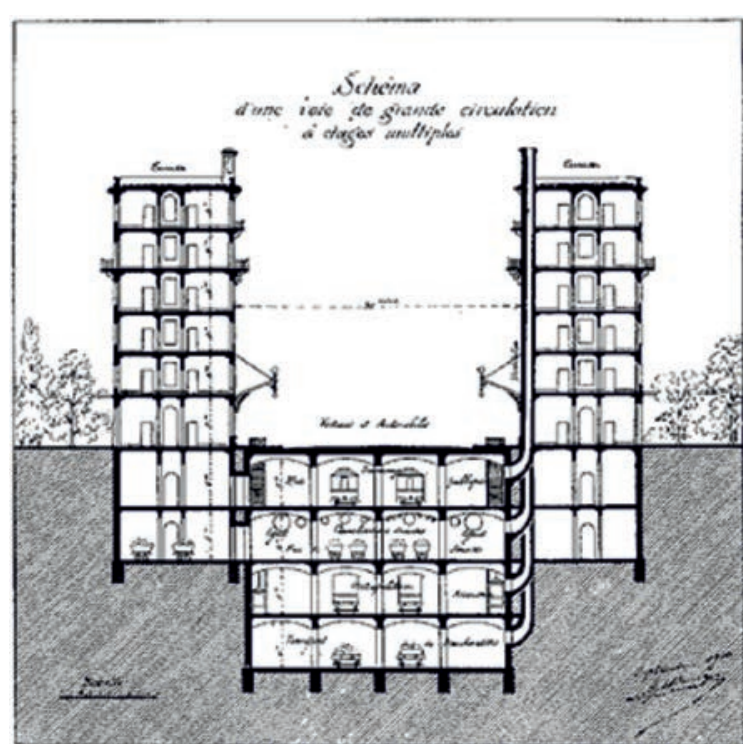


heless, the peculiarity of this multi-level design for heavy-traffic streets lays out a precedent for significant features of the linear megastructure concepts yet to come. The expansion of his plan shows a four-level subterranean division. The first underground level would be dedicated to pedestrians and carriages, second for tramways, hird for various pipes and infrastructure and fourth for transportation of different goods. The plan futuristic ambition is also reflected in the proposition of using roof terraces as landing platforms for airplanes. Henard himself acknowledges that the concept would be hard to realize in existing urban settings and would rather require planning of a completely new urban area, to sustainable clean urban living.

\section{Various concepts of linear megastructure}

The term "megastructure" has been used to describe similar structures of grand scale first time in the 1960s being especially popular in Japan among architects of the Metabolism movement. Apart from being an architectural concept, the term is applied to exceptional large-scale objects in civil engineering, space technology, nuclear research etc. Nonetheless, we find it necessary to distinguish the specific type of transit oriented compact city development structure apart from other various forms of megastructural projects by formulating the term "linear megastructure" as defined previously in this paper. Interestingly, there have been ample number of concepts introducing the idea of linear megastructure. Some emerged influenced by others and some appeared without acknowledgement of precedent examples. The ones presented in this research are a selection of several plans introduced throughout the course of histo-

\section{Edgar Chambless' Roadtown, 1910 (Source: Chambless, 2012)-}

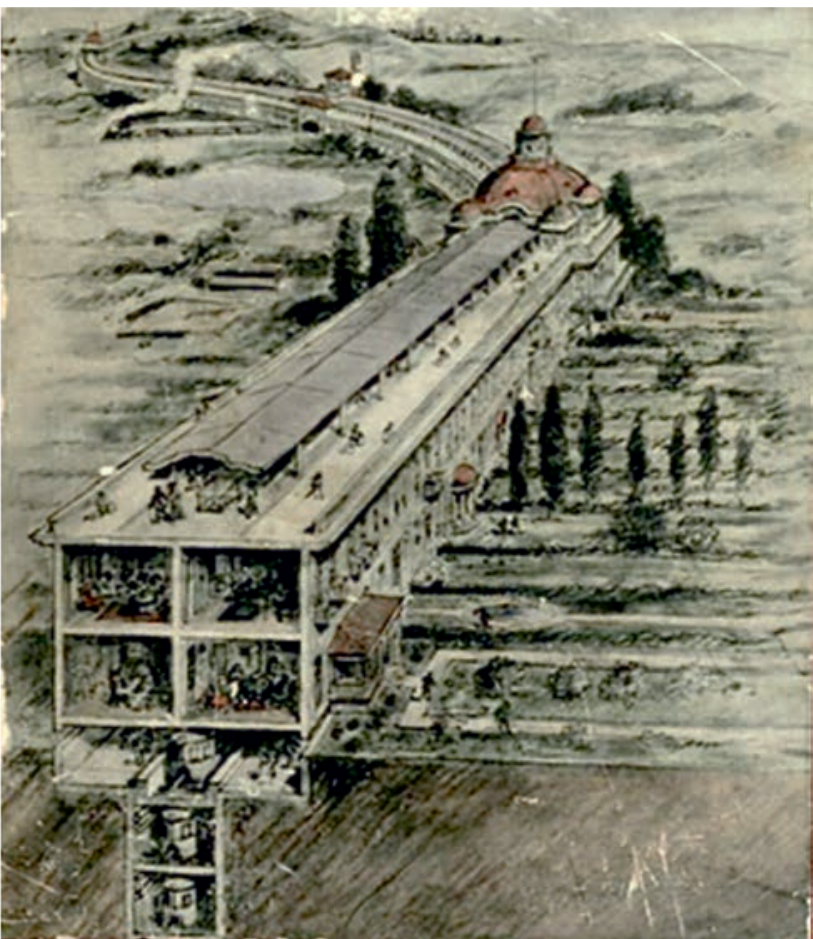

ry and triggered by various ideologies and socio-economic circumstances.

First to introduce the idea of an infinite inhabited linear structure connected to transportation systems was visionary Edgar Chambless with his proposa for Roadtown in 1910 .

While contemplating on the issue of land value an its dependency on transportation vicinity, Chambless, who also worked as a patent investigato dealing with new inventions, came up with a new concept of urban living.

The idea occurred to me to lay the modern skyscraper on its side and run the elevators and the pipes and wires horizontally instead of vertically."

Chambless envisioned Roadtown as joined sytransportation. He criticized the wasteful man and which goods are prepared from production to consumption and the high rates of unnecessary cost of various machineries, transportation and mediators that could be avoided by implementing a better coordinated system on a single transportation line. Roadtown was envisioned as a line of city through the country not more than two stories high with subterranean train transportation. The train planned for this project was the Boyes Monorail with rails made of wood and an estimated speed of 20 miles per hour - an invention that was never developed. Every household unit would have access to the lower monorail platform as well as an upper street on the roof. The street was planned as a space for leisure, cycling and recreation with a centra covered promenade, enclosed in glass with regulated heat in wintertime. In addition, Chambless went into great detail organizing all socio-economic aspects of his plan. No part of Roadtown design has ever been executed in reality.

Le Corbusier, one of the most prominent names of $20^{\text {th }}$ century architecture and Modernism, was also among the ones to produce a proposal for a linea megastructure. We know for certain that in his city planning ideas Le Corbusier was inspired by line ar city plans of Soria y Mata, Milyutin and Garnier. Whether he was a proponent of Chambless' congiers called Plan Obus (French for "cannon giend plans for Rio de Janeiro in 1930s display similar basic features of Chambless' vision.

highailding-aqueducta multi kilometer continuoncepts comprised of story housing beneath elevated highway linking a new business district of Algiers on one side to a new residential quarter on another Based on Roman aqueducts, his concept for Rio consisted of a continuous high-rise structure on piers with a wide motorway on top linking all the hilltops. Although a dominant III. in architecture of the Modernist era, Le Corbusier's town planning ideas were often criticized as being monotonous, car-

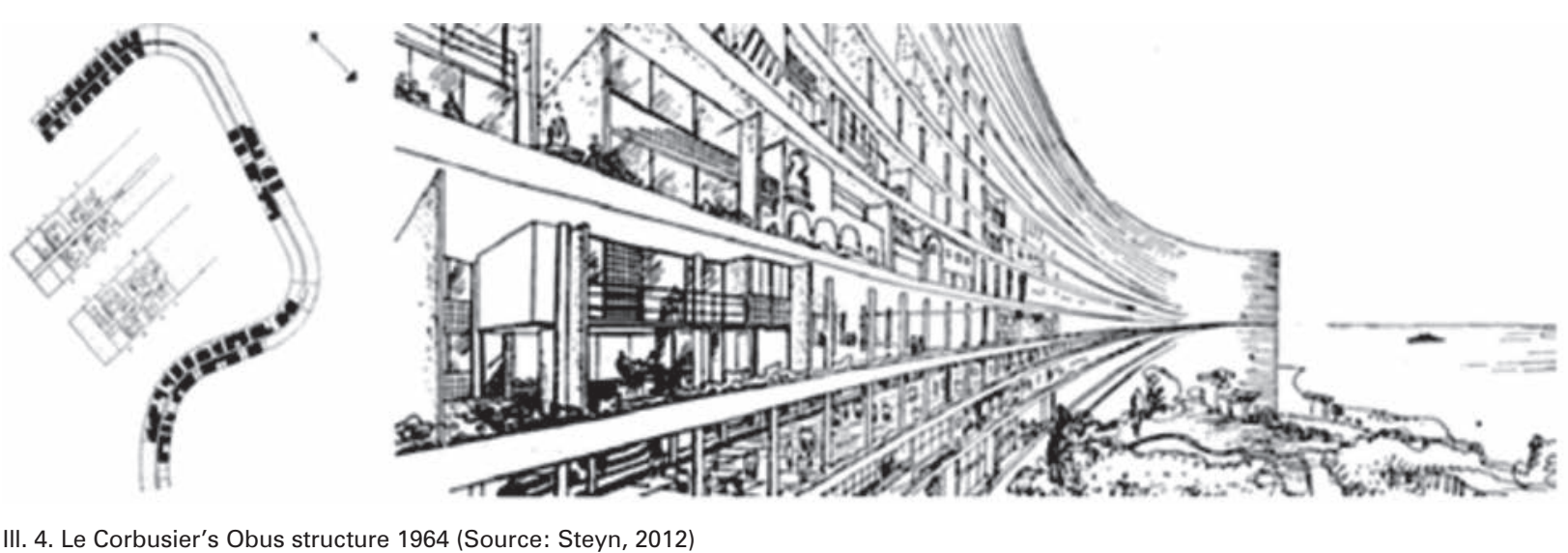

III. 4. Le Corbusier's Obus structure 1964 (Source: Steyn, 2012)

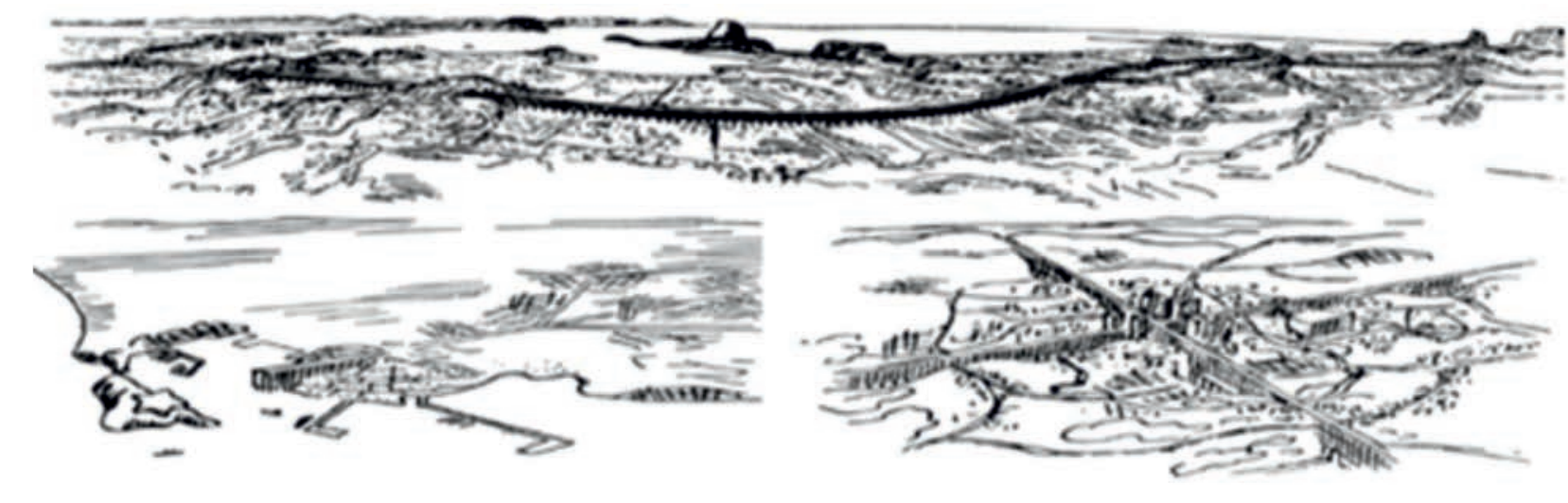

III. 5. Le Corbusier's proposal for linear structure in Rio de Janeiro (Source: Steyn, 2012)

-dependent and rudimental (Steyn 2012). The plan for Algiers however was addionally viewed as an audacious attempt in colonial urbanism separating and ignoring the local Algerian inhabitants by connecting two European colonialized parts of the city. Furthermore, the designed 180000 inhabitants' compartmentalized lifestyle and economic status would differ greatly compared to the Algerians'. Needless to say, his plans for Algiers an

Le Corbusier's concept although linear and although megastructural, differ in many ways from other concepts presented in this research. Their motivation is not in mitigating sustainability challenges as much as follo wing an ideological path established by the author. Megastructural architecture and planning was highly popular in 1960s Japan. The movement was influenced nist vision of a city as a machine viewed it as an organic procs. The movement came as a respons to the postindustrial economic reorganization and rapid urban growth. The most prominent III. of Metabolism theory Kenzo Tange, introduced his project for the Tokyo Bay area titled "A plan for Tokyo, 1960 - Towards a Structura Reorganization". The plan came as an answer to a cities challenge of rapid urban growth within an old physica framework. The transportation system was of significant importance in his plan with a clear hierarchical arrange ment of circulation. The plan consists of a system of traffic loops, having the first one frame the existing center of Tokyo. The plan was further laid out over water exp ded to reduce the stress of population growth on the city offering satellite tent-like residential units connect to the central axis. which of the city, the nervous system structure of the city." (Lin 2007)

Tange's plan was never carried out due to technical and socio-political challenges. However, it encouraged future plans to expand onto the Bay are contributing to the credibility of such megastruc-

contemporary example of linear megastructures is Paolo Soleri's Lean Linear City concept in 2010. Soleri's plan in theoretical sense is incomplete because it fails to acknowledge previous precedent concepts of linear megastructhres. The critique in Lean Linear City is oriented towards materialism, consumerism and the pursuit of individual spatial ownership of land stimulating urban sprawl. The project is a response to mitigating predicted high rate of urban growth, especially in places like China and India. The plan is envisioned as an energy efficient system with a low ecological footprint spreading in a "lean" 
accompanying the idea of integrating housing, infrastructure and transport in linear planning.

hanalyzing the various concepts of inear megastructure several common aspects can be noted:

the presented plans were influenced by different socio-economic circumstances over the course of history all the concepts were regarded by their creators as ideal cities serving as models for future urban development

the emphasis on importance of transport communication was consistent in all plans and they were based on the pursuit of best uifzalion of land and transpo relationship

we Corbusier's plans all were initially motivated by sultainability

the time of

were hard to completely new urban setting and in existing ones

none of the plans was ever realized in its full form and

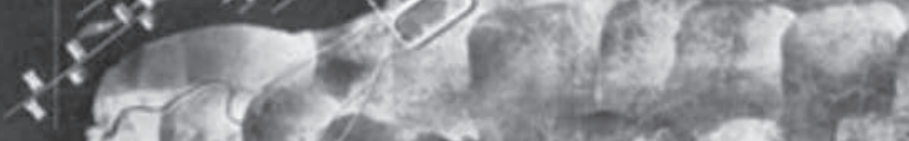

II. 6. KenzoTange's Tokyo Bay Project (Source: Lin, 2007)

and linear way from one cultural interest or economic need to another. The plan consists of three major modes of transportation; pedestrian walkways, cycling path and mass transit systems. A wide internal city park with water stream is envisioned separating two continuous housing structures carrying wind generators on the rooftops. A so-called terra level dedicated to cycling path and pedestrian walkways spans across both structures connected by bridges. Additionally, the plan consists of photovoltaic ribbons for solar energy, greenhouses and light wells for natural light to reach interior areas. As it

III. 7. Section rendering of Lean Linear City (Source: Soleri, 2012)

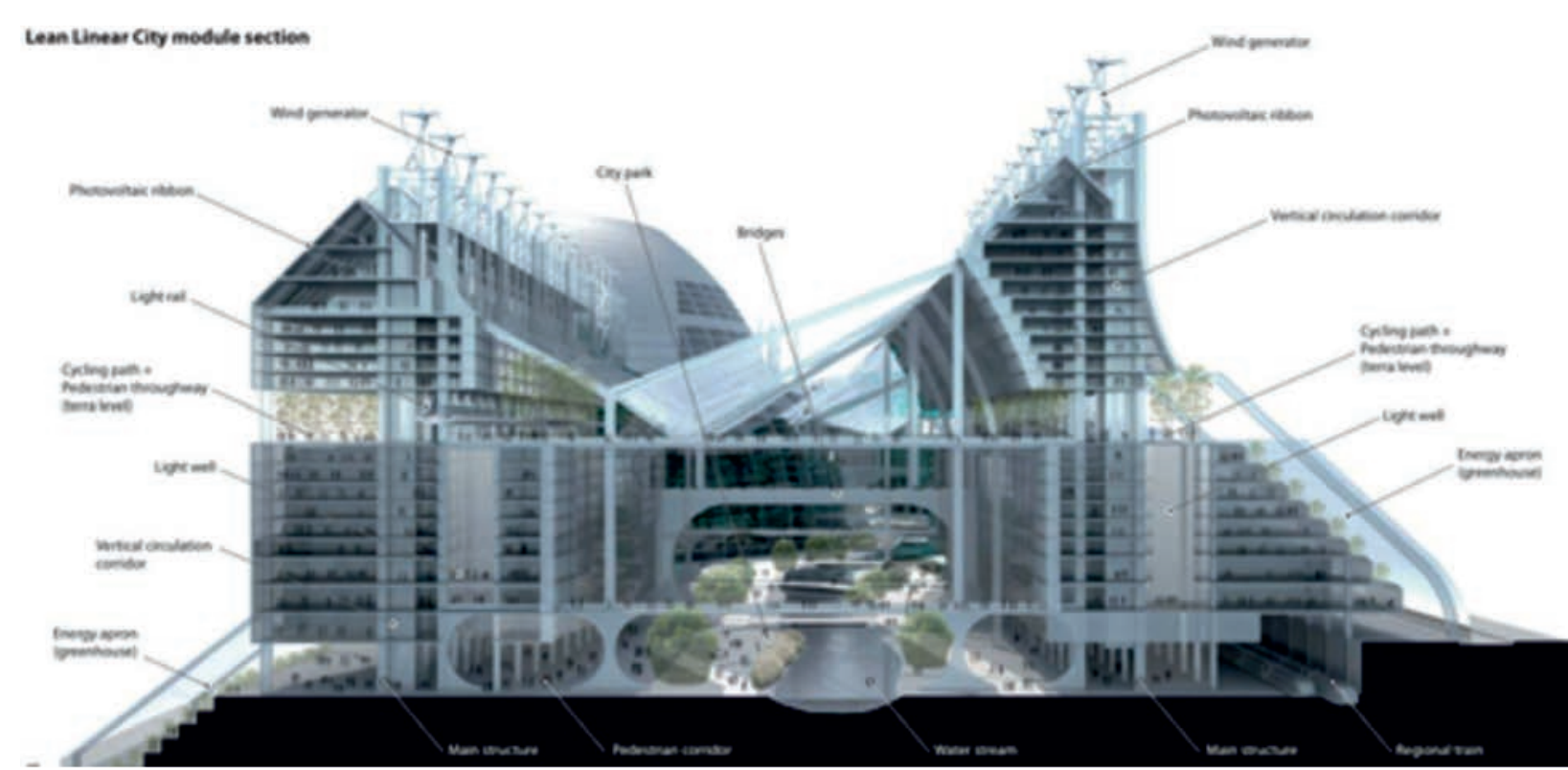

is with all previous linear megastructure concepts, Soler's Lean Linear City was never realized either.

\section{Conclusion}

It is important to note that the concept of linear megastructures cannot be fully separated from the context of linear urban development and its historical precedents pioneered by Arturo Soria y Mata's Ciudad de Lineal in Madrid in 1890s (Tufek-MemiseVic, 2018). This in Madrid in $1890 \mathrm{~s}$ (Tufek-Med more
The daunting grandeur of linear megastructure concepts' is most certainly a reason for the failure of their implementation in reality. The main issue here is the strive to formulate a general model of "ideal" living which in our world of versatile culture, various importance of places, genius loci, different attraction forces driving the form of urban environment- in its essence is not a concept of reality.

Additionally, the exaggerated scale provokes the labeling of Utopia which is mostly a cause for the unjust immediate rejection of otherwise not so unrealistic beneficia eatures that could be extracted from the concepts. Fast forward centuries after Leonardo's scheme with canals goods (similar to Henard's subterranean concepts) to Chicago's Wacker. Drive double-deck street project initiated in the 1920s. Wacker Drivem a 2.2 mile long two-level street following the iver along Chicago's downtown coop in its upper level is intended for local fratic and traffic and servicing buildings along the street with dedicated unloading spaces. Not an unrealistic feature of precedent "radical" design after al.

Kenzo Tange's Tokyo Bay project as controversia as it seemed at the time, encouraged later projects oriented towards land reclamation in the Bay 作 frastructural and architectural planning opposed to disperse zoning methods.

Finally, the ever growing contemporary trend in transit oriented development is essentially a combination of the aspirations for sustainable urban development, such as efficient energy consumption, walkable comnus fries, car-independent transporwith, eco-frendly hing envionte coupled wystems - the basis of proposals in liner mega ucture concepts.

BIBLIOGRAPHY

11) Banham, Reyner, and Cedric Price. 1999. Critic Writes-Selected
Essays by Reyner Banham. University Of California Press. 2] Cathcart, Richard B. 1996. Gauthier's 'Linear City.' En SO37 68929000039114. 2012 Roadtom. Place of publication not [3] Chambless, Edgar. 2012. Roadtown. Place of publication not
identified: Nabu Press. [4] Corbusier, Le. 2013. The City of To-Morrow and Its Planning,
New York: Dover Publications Inc. 2019. HENARD, CITTES OF THE FUTURE. Accessed Novent nell.edu/DOCS hienard.htm.
[5] Kostof, Spiro. 1992. The City Assembled the Elements of Urban Form through History. New York, NY: Thames \& Hudson.
[6] Lin, Zhong-Jie. 2007. "From Megastructure to Megalopolis: For-
mation and Transformation of Mega-Projects in Tokyo Bay." Journ of Urban Design 12 (1): 73-92. doi: 10.1080/13574800601072442. Highway Airspace to Work." Journal of Urban Design 9 (1): 47-71.

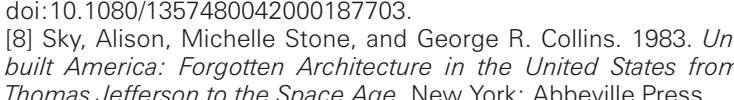
Thomas Jefferson to the Space Age. New York: Abbeville Press.
[9] Soleri, Paalo. 2012. Lean Linear City: Arterial Arcology. Mayer.

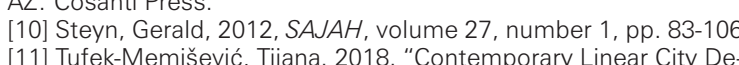
111] Tufek-Memišević, Tijana. 2018. "Contemporary Linear City De-
velopment: A Case of Spatial Interventions in Sarajevo, Bosnia and Herzegovina: Doc
sity of Technology 